\title{
POR ENTRE OS CASTANHAIS: SUJEITOS E LUGARES NO POVOADO FORTALEZA EM SÃO GERALDO DO ARAGUAIA, PARÁ
}

\author{
Eliseu Pereira de Brito \\ Universidade Federal do Tocantins, Curso de Geografia, Araguaína, TO, Brasil \\ eliseubrito@uft.edu.br \\ Samuel Santos Silva \\ Secretaria de Educação do Estado do Pará, São Geraldo do Araguaia, PA, Brasil \\ samoelss10@gmail.com
}

\begin{abstract}
RESUMO
O presente artigo discute questões concernentes ao ciclo econômico da castanha-do-pará com foco nos sujeitos castanheiros do povoado Fortaleza, localizado na bacia hidrográfica do Rio Itacaiúnas, em São Geraldo do Araguaia, Pará. Tem por escopo compreender a constituição e os dilemas dos atores castanheiros do Povoado Fortaleza; entender a formação do território castanheiro na região da bacia hidrográfica do Itacaiúnas a partir das vivências de tais atores; analisar os modos de vida passados e presentes dos castanheiros de Fortaleza, identificando o pertencimento deles à identidade castanheira. O modo de fazer a pesquisa foi por meio do método descritivo exploratório, com entrevistas e revisão em informações históricas, objetivando a compreensão da formação do território dos castanheiros. O extrativismo da castanha-do-pará se constituiu como tema de grande valor no entendimento de questões ocorridas na região da bacia do Itacaiúnas, no sudeste paraense. Organizada por meio da economia de aviamento, ela representa a introdução pioneira de processos econômicos e ocupação regional. A partir desse estudo verificamos as relações de poder presentes nos castanhais e a produção dos modos de vida passado e atual dos castanheiros de Fortaleza. Percebemos, com a pesquisa, que a semisservidão imposta aos sujeitos dos castanhais dificulta a criação de uma identificação com o trabalho de castanheiro, todavia, foi importante para construir uma identidade territorial.
\end{abstract}

Palavras-chaves: Território Castanheiro. Castanheiros. Povoado Fortaleza.

\section{BETWEEN THE CASTANHAIS: SUBJECTS AND PLACES IN THE PEOPLE FORTALEZA IN SÃO GERALDO DO ARAGUAIA, PARÁ}

\begin{abstract}
The present article discusses questions concerning the economic cycle of the Chestnut-doPará with focus on the chestnut individuals of the Povoado Fortaleza, located within the Itacaiúnas River Basin, in São Geraldo do Araguaia, Pará. Its purpose is to understand the constitution and dilemmas of chestnut actors of the Povoado Fortaleza; understand the formation of chestnut land in the region of the Itacaiúnas watershed from the experiences of such actors; to analyze the past and present ways of life of the chestnut trees of Fortaleza identifying their belonging in the chestnut identity. The way of doing the research was through the exploratory descriptive method with interviews and review of historical information, aiming the understanding of the formation of the chestnutland territory. The extractivism of Brazil nut was a valuable topic in the understanding of issues in the region of the Itacaiúnas Basin in southeastern Pará. Organized through the economy of aviamento, it represents the pioneering introduction of economic processes and regional occupation. From this study we verify the power relations present in the chestnut trees and the production of the past and current ways of life of the Castanheiros de Fortaleza. We realized with the research that the semi-servitude imposed on the subjects of the chestnut trees makes it difficult to create an identification with the chestnut work, but that it was important to construct a territorial identity.
\end{abstract}

Keywords: Chestnut woodland. Chestnut trees. District of Fortaleza.

\begin{tabular}{llllll}
\hline Caminhos de Geografia & Uberlândia - MG & v. 21, n. 73 & Mar/2020 & p. 415-428 & Página 415
\end{tabular}




\section{INTRODUÇÃO}

O presente estudo discute questões relacionadas ao ciclo econômico da castanha-do-pará concentrando-se nos castanheiros do povoado Fortaleza, em São Geraldo do Araguaia (PA). O estudo foi desenvolvido por meio de uma pesquisa histórica, buscando compreender a formação do território dos castanheiros e suas "interfaces" na produção espacial. Fez-se necessária uma revisão bibliográfica com base em autores relevantes que abordam a temática da castanha-do-pará e do território.

O extrativismo da castanha-do-pará se constitui como tema de grande valor para o entendimento de questões ocorridas na região do Itacaiúnas, onde fica o povoado Fortaleza, sudeste paraense. Simboliza a introdução pioneira de processos econômicos globais, que mantiveram os atores sociais, castanheiros, no caso, subjugados. São justamente tais sujeitos, assim como o local de suas respectivas atuações, o foco do estudo e sobre tais pressupostos destacam-se os seguintes questionamentos: como se dá a constituição do território castanheiro do Itacaiúnas? Como viviam e vivem tais sujeitos? Identificam-se com a atividade castanheira? São essas as indagações centrais que possibilitaram a construção desta pesquisa.

Este trabalho tem por escopo analisar a formação do território castanheiro na região da bacia hidrográfica do Itacaiúnas a partir das vivências, construindo entendimentos dos modos de vida passada e presente dos castanheiros de Fortaleza, estudo que objetivou a verificação da identidade dos sujeitos castanheiros, principalmente a identidade territorial, a qual tem como fundamento o homem nos castanhais e seu sentindo de pertencimento com o ofício do trabalho castanheiro.

O artigo está dividido em quatro tópicos: no primeiro discutimos o aporte teórico e metodológico da pesquisa; o segundo tópico traz o contexto histórico do ciclo da castanha-do-pará, importância econômica e contribuição para a migração na Amazônia Oriental; a terceira parte debate a situação de trabalho e o aviamento nos castanhais; a última parte analisa os resultados da pesquisa, ou seja, aborda o território castanheiro no Itacaiúnas, os modos de vida passados e presente dos castanheiros de Fortaleza e a identidade castanheira.

\section{CAMINHOS METODOLÓGICOS/TEÓRICOS}

O que se segue na primeira parte deste trabalho é o conjunto de procedimentos e ações os quais nortearam a preparação e a execução da pesquisa e posterior elaboração deste artigo. O presente tópico também discorre sobre os conceitos de território, migração e trabalho ligados ao objeto de estudo.

No que remete à revisão bibliográfica foram elaborados fichamentos com o intuito de facilitar o processo de redação do texto e, por se tratar de uma pesquisa qualitativa, para a coleta dos dados foram feitas entrevistas semiestruturadas de caráter participativo, o que conforme Verdejo (2006) propicia um ambiente aberto de diálogo e permite à pessoa entrevistada se expressar livremente sem as limitações criadas por um roteiro. As entrevistas feitas em campo partiram de diálogos com os sujeitos dos castanhais do povoado Fortaleza. Tais diálogos foram gravados e transcritos, possibilitando assim uma melhor análise dos resultados.

Sobre o conceito de território é proposta discussão tomando por base Raffestin (1993) e as multiterritorialidades em Haesbaert (2005). A partir do território serão tecidas proposições sobre os castanheiros as quais, a posteriori, serão expostas. Sobre o território, o supracitado autor destaca:

O território se forma a partir do espaço, é resultado de uma ação conduzida por um ator sintagmático (ator que realiza um programa) em qualquer nível. A se apropriar de um espaço, concreta ou abstratamente (por exemplo, pela representação), o ator 'territorializa' o espaço (RAFFESTIN, 1993, p. 143).

Para o autor, o território é derivado do espaço, ou seja, é o espaço produzido no qual atores sintagmáticos demonstram intenções e constroem territorialidades, permeando o espaço-tempo. A diferença entre ambos parte da premissa na qual o espaço é preexistente à ação humana, existe como algo dado, primitivo, enquanto o território se vale a partir da manifestação do homem que dele se apropria.

Sobre o espaço, o mencionado autor conceitua-o como um campo de possibilidades corroboradas a partir do momento em que o ator constrói territórios. "Local de possibilidades é a realidade material preexistente a qualquer conhecimento e a qualquer prática dos quais será o objeto a partir do momento em que um ator manifeste a intenção de se apoderar." (RAFFESTIN, 1993, p. 144. 
Concernente ao local de possibilidades realça-se que um ator só irá materializar as alternativas concebíveis a ele estabelecidas a partir de sistemas sêmicos ou códigos herdados de seus predecessores e consubstanciadas a partir de relações de poder.

Em relação aos conceitos de migração e trabalho foram levantadas ponderações relacionadas à fronteira e aos boias-frias migrantes, fundamentando-se em Martins (1996) e em Moraes (1999), respectivamente, assim como a questão do trabalho analisado por Sennett (2009) com o intuito de entender a situação nos castanhais de Fortaleza.

O processo migratório no Brasil pode ser entendido a partir da concepção de fronteira. A fronteira, sob essa ótica, não é político-administrativa, mas remete a uma dada área de encontros entre indivíduos com temporalidades e espacialidades diferentes. Para Martins (1996, p. 27), a fronteira:

À primeira vista é o lugar do encontro dos que por diferentes razões são diferentes entre si, como os índios de um lado e os civilizados de outro; como os grandes proprietários de terra, de um lado, e os camponeses pobres, de outro.

Esse lugar de encontro é composto por atores diversos, os quais possuem cosmovisões próprias e tempos históricos diferentes. Em torno dessas singularidades se firmam suas funções e interesses responsáveis, em certa medida, por seus deslocamentos rumo à fronteira.

O avanço da fronteira caracteriza-se pela intensificação migratória dos inúmeros agentes, dentre os quais os desprovidos da terra e o empresário, e na maioria das vezes haverá um injusto "litígio" entre tais sujeitos no território. "A história do recente deslocamento na fronteira é uma história de destruição. Mas, é também uma história de resistência, de revolta, de protesto, de sonho e de esperança" (MARTINS, 1996, p. 26).

Sobre as "disputas" existentes na fronteira, além dos exemplos ilustrados na Amazônia brasileira ressaltam-se os acontecimentos ocorridos no Vale do Jequitinhonha, norte de Minas Gerais, descritos por Moraes (1999). A expropriação das populações pobres dessa região em prol do agronegócio gerou distorções sociais e acarretou muitos problemas como a migração sobre a qual é afirmado o seguinte:

A violência dentro da lei e da ordem, patrocinada pelo Estado autoritário, traçou aos camponeses desta região o destino da migração definitiva ou da perpetuidade da migração temporária ou da exclusão social. Produziu-se uma multidão de eternos ausentes à procura de um tempo e de um lugar perdidos nas antigas veredas e chapadas (MORAES, 1999, p. 57).

As levas migratórias formadas no norte mineiro como resultado do não direito à terra imposta aos camponeses representam o descaso para com os desfavorecidos por parte do Estado brasileiro. Os camponeses se viram obrigados a retirar suas mudanças e se locomover à procura de empregos e, devido à sua baixa instrução se submeteram a situações subalternas.

Em conformidade com Moraes (1999), percebe-se que os migrantes do Vale do Jequitinhonha, apesar de terem sido arrancados da terra, mantiveram o senso de pertencer em relação à terra a qual outrora estava sob seus domínios, conforme o que se segue:

A representação do lugar, da terra de origem, constitui-se um elemento central da identidade destes trabalhadores. Expressões como "o lugar da gente", "a terra da gente", "aqui não é a terra da gente", formam o conteúdo do processo de reenraizamento, momento que corresponde à negação do desenraizamento imposto (MORAES, 1996, p. 211).

A autora expõe a relação identitária dos trabalhadores com o seu lugar de origem, uma identidade que tem no campo locativo sua construção. É importante frisar que há também uma identidade construída no trabalho, o cortador de cana, sujeitos que sabe corta e o vigor físico determinante na maior quantidade de cana cortada. Sennett (2009) chama a atenção da identidade com o trabalho ao discutir o ofício do padeiro entre o saber fazer e o saber manusear máquina. $O$ trabalho passou a ser visto como o "eu estranho", paradoxalmente, fácil de realizar e difícil de entender. "Operacionalmente, tudo é muito claro; emocionalmente, muito ilegível” (SENNETT, 2009, p. 79). Moraes (1996) chama atenção que a introdução da máquina no corte da cana reduziu os cortadores à condição de catadores de sobras do corte ou de rochas. Em se tratando dos castanheiros pode-se afirmar que há uma identidade construída no imaginário de migrante no processo da frente pioneira na Amazônia. Estes sujeitos relaciona o papel de migrantes como desbravadores, os que conseguiram "dominar" as matas e habitálas. Mais também é no trabalho que afirmam sua identidade de castanheiro. É o saber coletar e quebrar a castanha que define um castanheiro.

$\begin{array}{llllll}\text { Caminhos de Geografia } & \text { Uberlândia - MG } & \text { v. 21, n. 73 } & \text { Mar/2020 } & \text { p. 415-428 } & \text { Página } 417\end{array}$




\section{OS CASTANHAIS NO SUDESTE PARAENSE}

Explorada desde o início da colonização portuguesa na Amazônia, a castanha-do-pará teve sua produção valorizada a partir da primeira metade do século XX com a derrocada do ciclo da borracha. Conforme Almeida (2015), entre o fim do século XIX e o início do século XX a castanha já era o terceiro produto mais valioso para a economia regional.

No entanto, a economia regional só se voltou definitivamente para a extração da castanha-do-pará com a descoberta e a exploração dos castanhais localizados na região do médio Tocantins e sudeste do Pará.

Destaca-se o papel da cidade de Marabá, no período áureo da castanha-do-pará, devido à sua localização privilegiada às margens do Rio Tocantins e do seu importante tributário, Rio Itacaiúnas. Era em Marabá onde muitos "donos de castanhais" residiam ao menos na época da safra. Foi nessa cidade que se deu a relação castanheiro-aviador. Segundo Dias (1959, p. 84),

Marabá, na confluência do rio Itacaiúnas com o Tocantins, desenvolveu-se em virtude do comércio da castanha. O crescimento desta cidade como centro comercial, se fez pela localização privilegiada em relação às vias de escoamento dos produtos explorados no Médio Tocantins. Ela é a responsável pelo "aviamento" dos castanheiros, em virtude das boas instalações de suas casas comerciais. Localizamse em seu porto os armazéns para o estocamento da castanha, vinda da bacia do Itacaiúnas.

Salienta-se que, apesar de toda pujança, a economia da castanha enfrentou problemas concernentes à sua manutenção, a começar pelo escoamento da produção prejudicado pela inexistência de vias ligando Marabá a Belém. A opção viável eram os rios e mesmo assim havia obstáculos à navegabilidade devido à existência de cachoeiras e formações rochosas, no caso do Rio Tocantins, e à intermitência dos afluentes do Itacaiúnas no período seco. Sobre isso, Dias (1959, p. 86) assevera o seguinte:

Os igarapés, formadores dos afluentes do Itacaiúnas secam rapidamente e para que a castanha não fique presa é preciso aproveitar enquanto é possível a navegação. A existência de "travessões de areia" e de corredeiras nos cursos do Itacaiúnas e do Tocantins dificulta a navegação na época da estiagem.

Isso acarretava outros entraves, como a chegada tardia das castanhas a Belém, onde eram beneficiadas para poderem seguir rumo aos centros importadores. As castanhas exportadas eram matérias-primas de guloseimas consumidas, principalmente, na época natalina na Europa e nos Estados Unidos (DIAS, 1959).

No referente à extração da castanha, havia muita preocupação no que diz respeito ao armazenamento do produto ainda na selva, onde intempéries e excesso de umidade, contato com o solo encharcado e exposição ao sol poderiam causar prejuízos aos produtores. Com base em Almeida (2015, p. 75),

Para consolidar a boa aceitação que o produto estava tendo no exterior, um maior cuidado no processo de coleta e armazenamento da castanha se fazia necessário. Também eram evidentes os problemas provocados pela deterioração das mesmas, já conhecidos e estudados fora do Brasil.

Em virtude disso, instituiu-se a limpeza ou lavagem das castanhas nos centros primários ou até mesmo nos igarapés, como o exposto na figura 1. Tal procedimento torna-se obrigatório nos anos de 1920 muito por conta de exigências do mercado externo, o qual começava a questionar a qualidade do produto (ALMEIDA, 2015). 
Figura 1 - Igarapé Sororozinho, principal via para o escoamento da castanha da praça onde hoje se localiza o povoado Fortaleza.

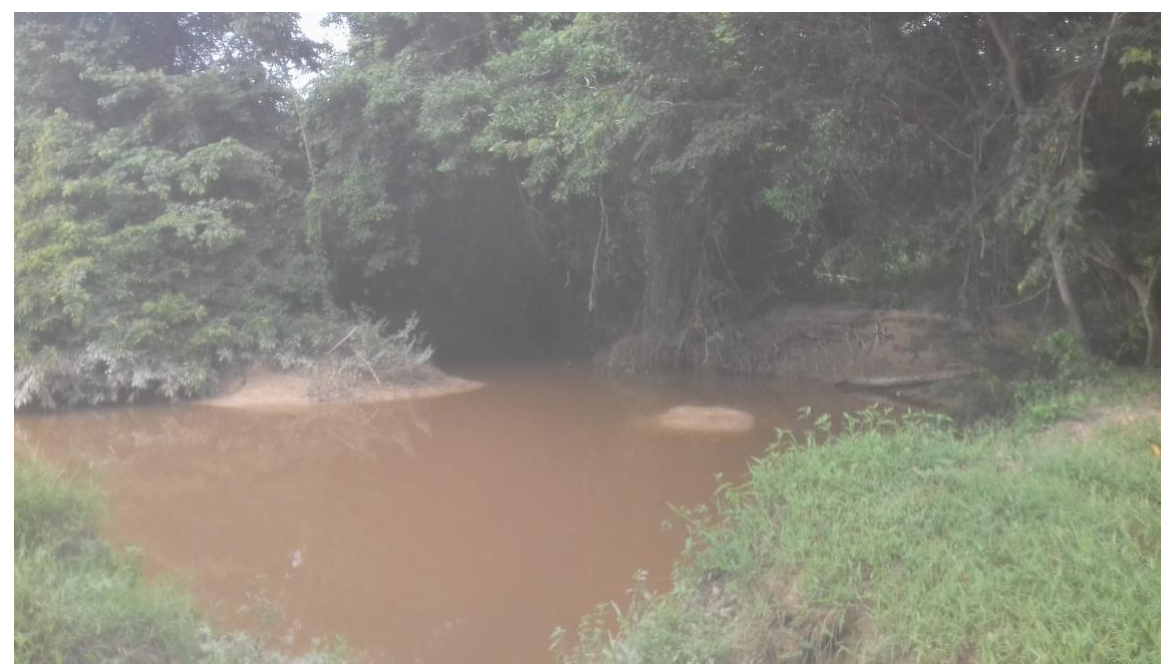

Fonte: autor (2018).

Outro obstáculo apresentado à comercialização da castanha era a sua forma de exportação, geralmente in natura. O fruto com casca é mais propício a circunstâncias de inutilização com o mofo, por exemplo, e junto a isso se ressaltam também as condições de armazenamento e transporte em direção aos centros importadores. Se não houvesse as condições específicas de temperatura e limpeza da produção no decorrer da viagem, a possibilidade de perder parte da mercadoria aumentava (DIAS, 1959).

Apesar desses problemas relacionados à exportação da castanha com casca, tal forma foi a predominante ao longo desse ciclo econômico. Almeida (2015, pp. 81-82) corrobora o seguinte sobre tal questão:

Contudo, apesar das vantagens apontadas em direção ao aperfeiçoamento ainda maior do beneficiamento da castanha-do-pará, nas décadas seguintes continuou a predominar a castanha com casca na pauta de exportações e o produto beneficiado não chegou a corresponder à metade do total exportado.

A castanha se manteve como produto importante para o mercado regional durante várias décadas, apesar do desdém por parte de intelectuais e políticos, ideia constatada por Almeida (2015, p. 27) a seguir:

Na visão comum que predominava entre os estudiosos e autoridades, o extrativismo vegetal teria inibido a agricultura, por não permitir a fixação da mão de obra, sempre atraída para o interior da floresta e com uma tendência dispersiva pelas facilidades em extrair os recursos disponíveis na natureza.

Em consonância com esse desprezo, os órgãos públicos pouco fizeram para melhorar as mencionadas situações, mesmo com toda a relevância da castanha no período. Suas áreas de atuação limitavam-se à partilha dos castanhais, em grande parte públicos, entre os interessados.

A primeira forma de cessão, largamente utilizada dos anos de 1920 em diante, foram os arrendamentos, os quais, para Emmi (2002, p. 6), eram "uma arma usada pela oligarquia castanheira para exercer o poder político e econômico sobre alguns médios e pequenos produtores que se dedicavam à coleta da castanha". Outro autor a tecer críticas relacionadas a essa forma de aquisição, dos direitos de explorar os castanhais, é Oliveira (1940, p. 5), o qual salienta o seguinte:

Esse sistema não é o mais indicado para um país que precisa mobilizar suas energias e ordenar sua economia. Explica-se facilmente que um arrendatário não procure fazer benfeitorias e radicar moradores em terrenos que na próxima safra poderão ser de outro dono.

O sistema de cessão por arrendamento era criticado pelos próprios "senhores dos castanhais" e aos poucos foi se deteriorando e sendo substituído por outros meios de repassar os castanhais aos requerentes. Segundo Emmi (2002, p. 7),

$\begin{array}{llllll}\text { Caminhos de Geografia } & \text { Uberlândia - MG } & \text { v. 21, n. 73 } & \text { Mar/2020 } & \text { p. 415-428 } & \text { Página } 419\end{array}$




\begin{abstract}
A partir de 1954 com a entrada em vigor da Lei n. 913, o aforamento se generaliza como forma principal de aquisição de castanhais. Essa forma de apropriação surgiu a partir de reivindicações dos grandes arrendatários de castanhais que passaram a postular não somente um tempo de permanência maior nas áreas de castanhais, uma vez que os arrendamentos eram temporários (contratos por uma ou mais safras), mas uma apropriação de fato das áreas de castanhais e de maneira permanente.
\end{abstract}

Essa nova lógica trouxe benefícios, somente, para os foreiros, pois expandiram sua influência regional e autonomia sobre a produção. A concessão por aforamento restringiu ainda mais o acesso aos castanhais, ou seja, cada vez mais passaram a concentrar-se nas mãos de poucos. "Se agruparmos os foreiros por famílias, aparece de maneira mais clara a concentração das áreas de castanhais." (EMMI, 2002, p. 7).

No entanto, a partir da década de 1950, a constituição da Amazônia Legal e os projetos de integração nacional anunciaram o declínio das lógicas produtivistas tradicionais e extrativismo, em face de novos meios de produção agropecuária e mineral.

No sudeste do Pará dos dias atuais, como mostrado na figura 2, as castanheiras ainda estão presentes no ambiente, mesmo que em menor quantidade e de forma isolada. Essas árvores sobreviventes são retratos de um passado recente em que eram as "rainhas" dessas terras, sendo que devido a políticas equivocadas e predatórias foram "destronadas" pelos rebanhos bovinos.

Figura 2 - Castanheira nas proximidades do povoado Fortaleza.

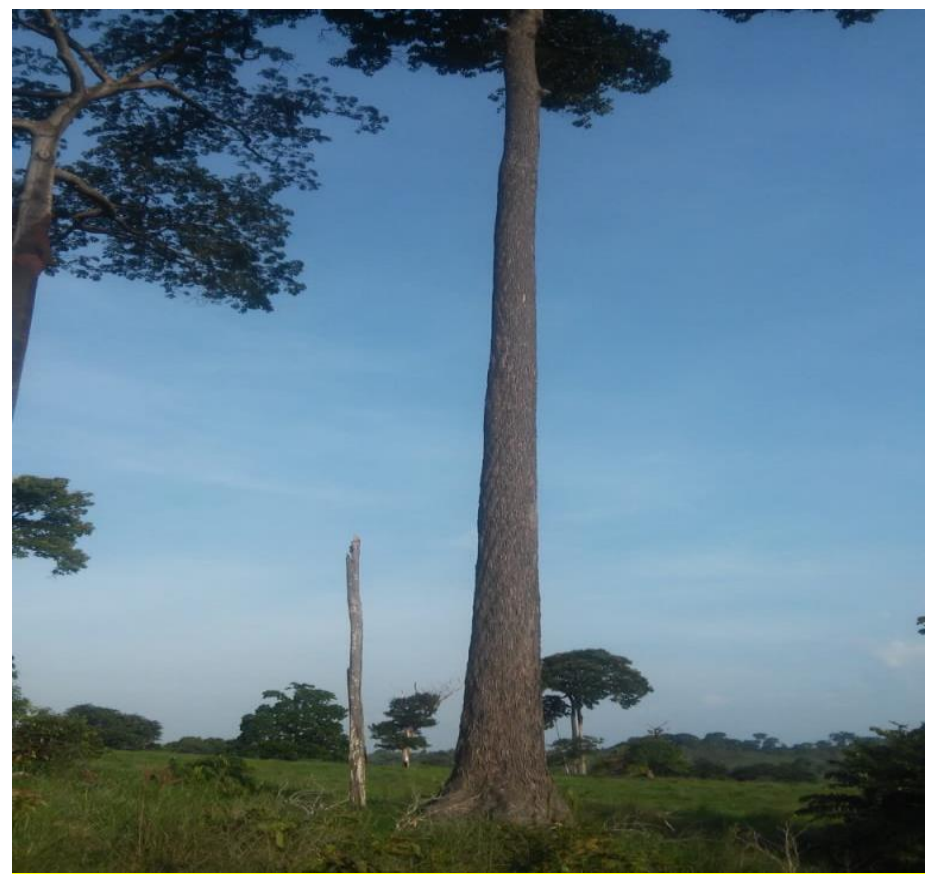

Fonte: autor (2018).

Atualmente, as castanhas ainda são comercializadas em muitas cidades do sudeste do Pará, como São Geraldo do Araguaia, a 160 km ao sul de Marabá, onde são encontradas no Porto das Balsas na beira-rio e em barracas próximas a um dos principais supermercados locais na principal avenida da cidade.

\title{
OS CASTANHEIROS E O PROCESSO MIGRATÓRIO NA AMAZÔNIA ORIENTAL
}

No que se refere à migração para a Amazônia é habitual falar das duas ondas migratórias direcionadas para a região em períodos diferentes e compostas por diversos grupos. Primeiro houve o intenso fluxo do ciclo da borracha, no qual migrantes provenientes, principalmente, da Região Nordeste ocuparam a floresta na busca por seringueiras permanecendo, em alguns casos, após a queda da economia do látex. Dos anos de 1960 em diante, a investida dos militares, com o projeto de integração nacional,

$\begin{array}{llllll}\text { Caminhos de Geografia } & \text { Uberlândia - MG } & \text { v. 21, n. 73 } & \text { Mar/2020 } & \text { p. 415-428 } & \text { Página } 420\end{array}$


ligou a Amazônia ao restante do país, ocasionando uma segunda onda migratória mais intensa e devastadora rumo à Amazônia, que ainda se manifesta em determinadas áreas regionais.

Entre os dois períodos mencionados, o ciclo da borracha e a integração nacional, a Região Amazônica ficou entre o isolamento e migrações esporádicas dentre as quais, apesar de ser em menor grau de intensidade comparada à migração direcionada para a exploração da borracha, merece destaque o movimento dos castanheiros para o médio Tocantins paraense oriundo do baixo Tocantins, norte goiano (Estado de Tocantins, atualmente) e Maranhão, principalmente. "É impressionante a força atrativa que a região do Itacaiúnas exerce sobre a população das regiões do baixo Tocantins e do sertão maranhense e goiano" (DIAS, 1959, p. 82)

A atração desses indivíduos em direção ao sudeste do Pará tem a ver com a procura de um novo trabalho em regiões de crescimento acentuado. O surgimento de novas oportunidades de "ganhar a vida" mais facilmente, por razão da falta de alternativa em suas terras, era visto como algo irrecusável aos sertanejos dessas regiões.

Por conta disso, a intensificação da extração da castanha no Sudeste paraense reuniu grupos migrantes aos castanhais onde ficaram à mercê da própria sorte, enfrentando os indígenas, doenças e outros percalços com o intuito de recolher o máximo de ouriços possível. Essas migrações, geralmente, eram espontâneas e, de acordo com Braz (2003), ocorria o seguinte:

Gente chega de todos os cantos, mormente homens, com a esperança de um bom dinheiro na safra. Os barracões ficam cheios deles: paraibanos, maranhenses, goianos, mineiros, cearenses, pernambucanos, todos sem naturalidade embarcam nos veículos ou nos motores de popa e sobem, geralmente o Itacaiúnas, para os distritos da escravatura esperançosa (BRAZ, 2003, apud SILVA, 2006, pp. 149-155)

Percebem-se duas categorias de migrantes existentes nesse período, o permanente e o sazonal. No primeiro caso, o indivíduo permanecia por tempo indeterminado e isso ocasionava um longo período de ócio, pois a safra da castanha se iniciava ao fim do ano e ia até meados de março. O outro grupo, formado pelos migrantes sazonais, regressava aos seus locais de origem, onde tinham família (ALMEIDA, 2015).

Essas formas de exploração eram vistas como problema pelo governo pela razão de não permitir a ligação do homem à terra por causa do caráter temporário da extração da castanha, o que fazia o governo exaltar a necessidade de inserção da agricultura em escala comercial na região dos castanhais. Almeida (2015, p. 67) observa que:

Apesar da importância crescente adquirida pela castanha, nos relatórios e mensagens enviadas pelos governadores do Pará, ao tratarem dos aspectos econômicos do Estado, o destaque maior continuava sendo a borracha e as esperanças eram colocadas novamente na agricultura, como meio de fomento para outras fontes de produção.

Graças ao extrativismo da castanha é que a região da bacia hidrográfica do Rio Itacaiúnas se viu tomada por diferentes agentes e esse novo quadro que se apresentou na Amazônia Oriental, ou seja, a chegada de massas de "estranhos" causou a alteração dos modos de vida dessa parte da Amazônia, sudeste do Pará. Os atores sintagmáticos se organizaram na dinâmica do território gerada na economia de aviamento sustentado por comandos internacionais geridos por bancos e casas exportadoras, comerciantes nas praças de venda da castanha e castanheiros. Mas como afirmou Haesbaert (2005) o território é múltiplo para os sujeitos e os castanheiros ao mesmo tempo que se organizaram na economia da castanha, enfrentaram a expansão da fronteira agrícola sobre seus territórios. $O$ desmatamento para formação dos pastos foi uma forma de desterritorialização dos sujeitos ao derrubar a floresta, lócus das castanheiras.

\section{LEITURAS DA ORGANIZAÇÃO DO TRABALHO NOS CASTANHAIS E DA ECONOMIA DE AVIAMENTO}

Muitos coletores de castanha iam a Marabá sem sequer ter a certeza de obtenção de empregos nos castanhais, pois só quando chegavam a essa cidade e se hospedavam nas pensões é que teriam contato com o proprietário ou gerente do castanhal para negociar os termos de serviço. "Normalmente, ao chegarem a Marabá os trabalhadores procuravam as pensões para poderem ser vistos e, posteriormente, contratados para o serviço de coleta. Muitas vezes, o castanheiro hospedava-se apenas com a roupa do corpo" (ALMEIDA, 2015, p. 107). 
Em relação aos aviadores eram comerciantes, em alguns casos podiam ser o proprietário do castanhal ou o homem de confiança dele, fornecedores de mantimentos e ferramentas necessárias para o extrativismo da castanha. O aviador ficava em Marabá, exceto nos casos de aviamento exercido pelo próprio senhor da castanha ou designado o qual se instala no meio da floresta, de onde gerencia a atividade extrativa. Dias (1959, p. 82) constata a seguinte relação:

Estabelece-se algumas vezes um pacto entre o 'patrão' e o 'camarada' no sentido de que a parte da castanha que lhe pertence seja vendida ao próprio patrão. Estes aviamentos são feitos na própria praça de Marabá e muitas vezes os patrões, para poderem financiar os castanheiros, vendem adiantadamente ao comércio ou pessoas que possuem castanhais a produção de seu castanhal.

O aviamento pressupõe relação, intermediada ou não, entre sujeitos com atribuições diferentes no seio da floresta. $\mathrm{O}$ aviador dispõe dos objetos necessários ao trabalho: embarcações, ferramentas e alimentos, enquanto o castanheiro possui as mãos, ou seja, a força de trabalho, e está desgarrado da terra, em muitos casos chega só com a roupa do corpo, facilitando os processos de exploração que permearam os castanhais do Itacaiúnas.

Ao subir os afluentes do Itacaiúnas, o castanheiro está em dívida com seu empregador, seu "pagamento adiantado" é o "de comer e o de vestir" e tem sobre as "costas" a responsabilidade de recolher quantitativo expressivo de castanhas; consubstancia-se aí condição análoga à escravidão, visto que "muito raramente o valor do adiantamento ou aviamento era coberto pelo trabalho do castanheiro, ficando este preso a um regime de servidão por dívidas com o dono do castanhal" (ALMEIDA, 2015, p. 112).

Na mata, os coletores se dividiam em grupos e dirigiam-se para pontos diferentes, onde montavam a colocação, acampamento levantado próximo aos castanhais, facilitando o processo de recolhimento dos ouriços de castanha, e iniciavam a coleta, findando-a quando atingiam boa quantidade de ouriços, os quais eram transportados para a praça, sede do castanhal. Almeida $(2015$, p. 107) reforça:

A organização administrativa de um castanhal era voltada para a reunião e o transporte do produto coletado na floresta. Na sede de um castanhal bem organizado ou barracão estavam os depósitos para a castanha "suja" e para a "lavada", os pequenos armazéns para o fornecimento de mercadorias e a casa do administrador.

Sem a praça, a produção no castanhal torna-se mais difícil, pelo fato de ela, como centro do castanhal, dispor da estrutura para o escoamento da mercadoria, embarcações ou animais e seu gerenciamento é simbolizado pelo barracão, onde fica o dono ou encarregado.

O trabalho nos castanhais é árduo, a floresta causa espanto e impõe limites ao trabalhador da castanha. Não há elo algum entre esse trabalhador e os castanhais. "Na hyloea tocantina, mais do que em qualquer outra região do país, nota-se o divórcio completo entre o homem e a terra. $\mathrm{O}$ explorador investe desaparelhado de tudo e desajudado de todos" (OLIVEIRA, 1940, p. 5).

Até mesmo a atividade exercida nos castanhais é estranha em razão de tratar-se em grande parte de homens acostumados à plantação, criação de gado e garimpagem em seus sertões de origem. A descaracterização do homem ante a terra, aliada à falta de investimentos públicos ou mesmo privados, é empecilho à execução de outras atividades na floresta.

As relações de trabalho impregnadas nos castanhais, representadas pelo aviamento, remetem ao mercantilismo e foram responsáveis pelas disparidades observadas na economia da castanha. Concomitante ao enriquecimento dos patrões, aviadores, comerciantes e outros atores houve o empobrecimento dos castanheiros, os quais, assim como a natureza, eram explorados nessa lógica produtiva vil e isso, certamente, foi um dos fatores essenciais para o declínio do extrativismo da castanha.

\section{HOMENS E MULHERES CASTANHEIRAS DO POVOADO FORTALEZA}

A primeira parte do tópico trará considerações remetendo-se aos sujeitos dos castanhais, principalmente os castanheiros, e à constituição de seus territórios com base em Raffestin (1993) e informações dadas por meio de entrevistas pelos castanheiros e tropeiros do povoado Fortaleza, antiga praça de castanha, localizado na área da bacia hidrográfica do Rio Itacaiúnas, como demonstrado na figura 3, no município de São Geraldo do Araguaia (PA), estando distante 72 km da sede municipal e 140 km de Marabá.

$\begin{array}{llllll}\text { Caminhos de Geografia } & \text { Uberlândia - MG } & \text { v. 21, n. 73 } & \text { Mar/2020 } & \text { p. 415-428 } & \text { Página } 422\end{array}$


Figura 3 - Localização do povoado Fortaleza, munícipio de São Geraldo do Araguaia (PA).

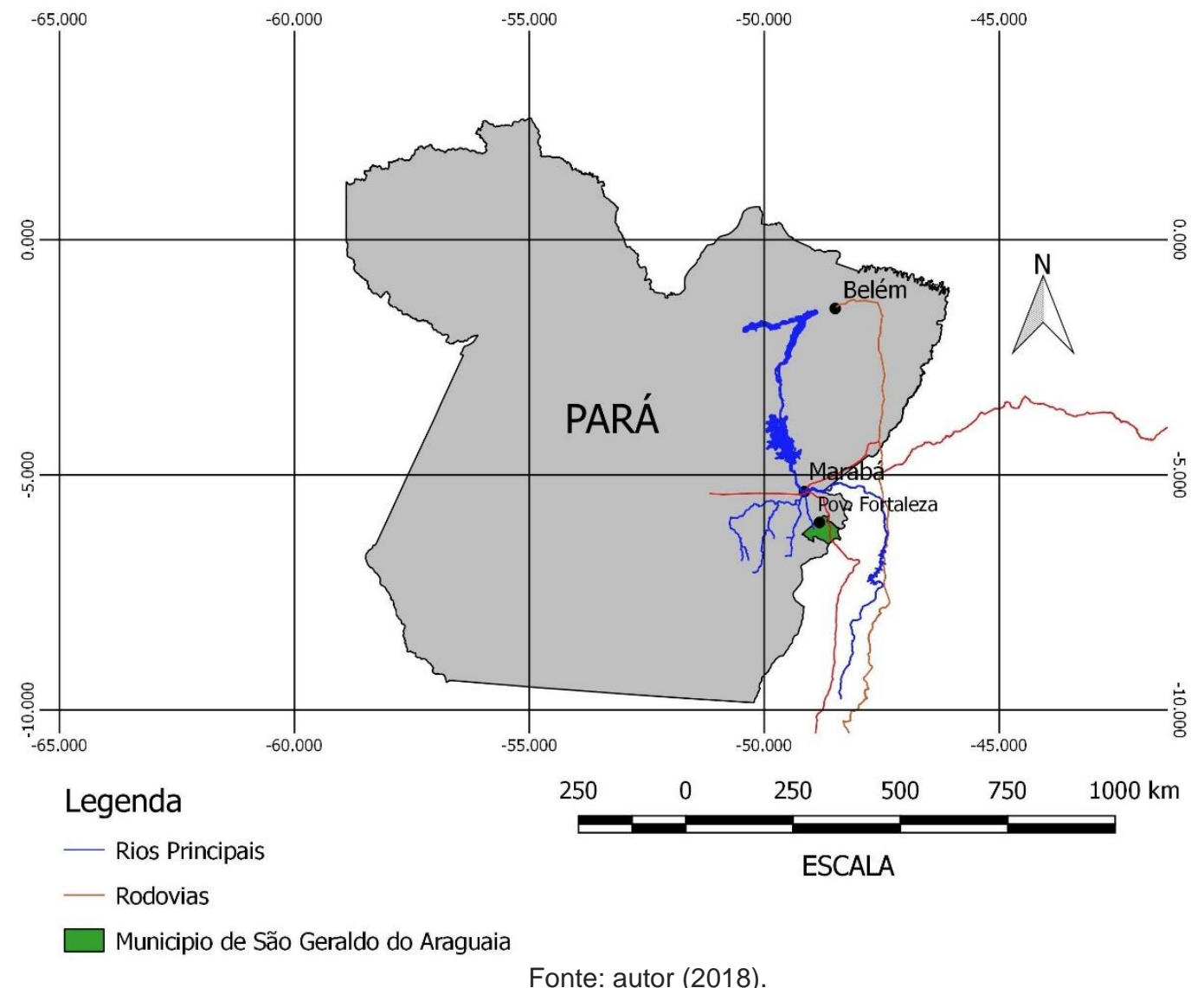

A presente pesquisa atentou-se à dualidade patrão/encarregado versus castanheiro/tropeiro. No tocante ao segundo grupo, em alguns casos, com base nos relatos obtidos em campo, há sujeitos que executaram ambas as funções ao longo de suas trajetórias sob os castanhais.

Os donos de castanhais introduziram na floresta novas formas de produção que moldaram as intencionalidades existentes ali, fazendo as atenções do Estado, a contragosto, voltarem-se para suas atividades. Com esse poderio mantiveram-se, orquestrando suas ações e desejos nos castanhais.

Em relação ao encarregado, ele representava a figura do porta-voz do patrão no castanhal, era quem dava as ordens, indicava os pontos de coleta para cada castanheiro e fazia a medição dos frutos. $\mathrm{Na}$ medição, em muitos casos faziam valer sua posição e fraudavam os volumes de castanhas, situação corroborada por autores como Almeida (2015) e Emmi (2002) e observar-se também na fala do entrevistado 3 o seguinte:

Eles media a castanha e acontecia muita vez da caixa de medir castanha que eles chama de hectolitro, aí colocava o bração de redor da caixa e botava a castanha, aí o cara tirava o braço levemente pra castanha ficar amontoada em cima da caixa, dava quase outra caixa em cima da caixa, tá entendendo? Era uma fraude ao vivo, assim, você vendo, mas não podia fazer nada porque era dessa forma que funcionava (ENTREVISTADO 3, nov. 2018, informação verbal).

Quanto aos castanheiros, cujo exemplo é apresentado na figura 4, desfavorecidos por diversas ações como a fraude supracitada, eram as peças essenciais nessa escala produtiva que os explorava, apesar de muitos não terem noção disso, denotando-se o servilismo. 
Figura 4 - Típico castanheiro do Médio Tocantins paraense equipado para adentrar os castanhais em meados dos anos 1970.

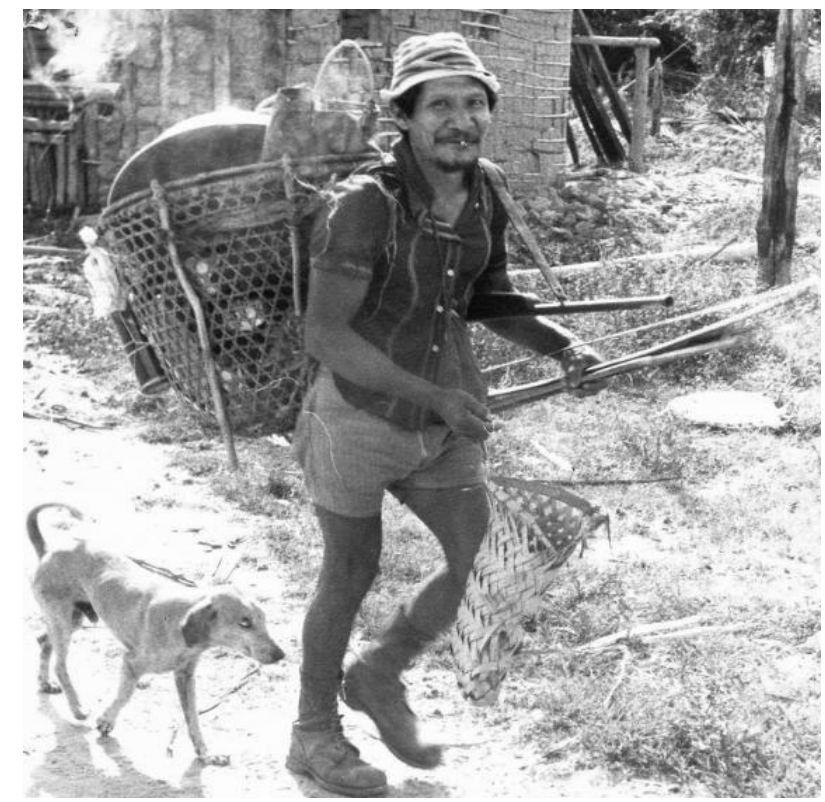

Fonte: Casa de Cultura de Marabá (nov. 2018).

Todavia, o castanheiro em grande parte do tempo estava fora do alcance dos "olhos do patrão", tinha sua liberdade e era oportuno aproveitar tais situações para criar mecanismos que servissem de contraponto à sua situação de servidão, como é afirmado pelo entrevistado 3 abaixo:

Às vez também era desonesto, sabe? Por exemplo, eu cortava nessa colocação aqui e tu na outra aí. A gente combinava, porque eles não aceitava catar na mesma que cortou, tu deixa castanha pra mim aqui e eu pra tu lá, isso nem sempre acontecia, mas aqueles castanheiros treteiros fazia isso. Aí o cara já ia sabendo que na colocação tinha castanha que o outro deixou (nov. 2018, informação verbal).

Portanto, o ato de "enrolar" o patrão era visto como uma forma de dar o troco e tentar de alguma forma diminuir o prejuízo nesse meio produtivo tão desigual. A realização de ações demonstrando suas objetivações, apesar de ser em grau inferior comparada às atividades exercidas por outros atores, evidencia o castanheiro como um ator sintagmático, assim como os demais envolvidos na extração da castanha, e sobre o qual Raffestin (1993, p. 152) postula o seguinte: "do Estado ao indivíduo, passando por todas as organizações pequenas ou grandes, encontram-se atores sintagmáticos que 'produzem' o território".

Ao se instalar na selva, o castanheiro precisava dispor dos meios para se manter, sendo necessário conhecer o ambiente inóspito e por meio de objetos trazidos de fora, dominá-lo. O castanheiro devia estar bem equipado e, segundo o entrevistado 3, "em determinado lugar os castanheiros tinha um paneiro nas costas, mocó, nome popular de um tipo de bolsa muito comum em determinados locais da região amazônica; de lado, facão e espingarda e às vez boné na cabeça" (nov. 2018, informação verbal).

Havia conhecimentos e práticas cuja aquisição era necessária pelos castanheiros, como a melhor hora para abater tal animal e a forma adequada de prepará-lo; os usos medicinais de uma determinada planta; as melhores árvores para construir um abrigo que protegesse da chuva e de animais perigosos, sendo esses só alguns dos saberes dos quais se deveriam apropriar. Sem esses conhecimentos, o sujeito virava presa fácil na selva e tornava-se inviável engendrar suas objetivações espaciais. Para Raffestin (1993, p. 144),

Todo projeto é sustentado por um conhecimento e uma prática, isto é, por ações e/ou comportamentos que, e claro, supõem a posse de códigos, de sistema sêmicos. É por esses sistemas sêmicos que se realizam as objetivações do espaço, que são processos sociais

Percebe-se que a atividade de tropeiro tinha mais prestígio ante ao castanheiro, pois, com base nos relatos de campo, esse "prestigio" só foi exercido pelo entrevistado após anos de trabalho na coleta. Soma-se a isso o fato de a tração animal se inserir nessa produção em larga escala, em anos

$\begin{array}{llllll}\text { Caminhos de Geografia } & \text { Uberlândia - MG } & \text { v. 21, n. 73 } & \text { Mar/2020 } & \text { p. 415-428 } & \text { Página } 424\end{array}$


posteriores à Segunda Guerra Mundial conforme Almeida (2015). Nesse período, a economia da castanha já estava consolidada e a inserção do transporte animal simbolizou uma evolução para tais processos, quem possuía tropa para "puxar" castanha era bem requisitado pelos senhores dos castanhais.

Os tropeiros, ao serem abarcados pela economia da castanha, ocasionaram rearranjos dentro dos castanhais, como a necessidade de alimentos e locais para o descanso da tropa. Outra alteração percebida se deu nas formas de transporte da castanha até o centro primário, logo, quando os níveis de água dos igarapés impossibilitavam a descida das castanhas, aos tropeiros cabia exercer tal função por terra até Marabá; na volta, traziam mercadorias para reabastecimento dos castanhais.

A implementação da tração animal na coleta da castanha pode ser vista como a gênese da lógica pecuarista que começava a se instalar nessa região e iria substituir o extrativismo vegetal no decorrer da segunda metade do século XX.

Constatam-se os diversos níveis de relações de poder intrínsecos ao meio produtivo da castanha, desde o dono do castanhal, que financiava a produção junto aos grandes comerciante exportadores em Belém, até o castanheiro e outros agentes incumbidos de exercer as tarefas mais laboriosas.

Nesta lógica produtiva da castanha-do-pará há uma ideia de tessitura, a qual, segundo Raffestin (1993, p. 154) "é sempre um enquadramento do poder ou de um poder. A escala da tessitura determina a escala dos poderes. Há os poderes que podem intervir em todas as escalas e aqueles que estão limitados às escalas dadas", verificam-se as delimitações presentes e o castanheiro tem suas ações limitadas às áreas de colocação; o encarregado comanda as atividades a partir da praça do castanhal e de forma parcial sobre o castanheiro presente no ponto de coleta; por conseguinte, o senhor do castanhal de Marabá, ou mesmo Belém, com visitas esporádicas aos castanhais, controla todo o processo extrativo até o ponto no qual precisa lidar com as classes políticas, comerciantes e donos de fábricas de beneficiamento.

\section{MODOS DE VIDA PASSADOS E PRESENTES DOS CASTANHEIROS DO POVOADO FORTALEZA}

Ao traçar um paralelo entre os modos vida atuais e passados dos residentes no povoado Fortaleza, em São Geraldo do Araguaia (PA), que trabalharam nos castanhais, é preciso considerar os contextos nos quais estavam inseridos.

Sobre o passado desses castanheiros, cuja temporalidade envolvida na produção da castanha delimitase dos anos de 1960 ao início dos anos de 1980, destaca-se o momento de transição pelo qual passava a Amazônia brasileira, principalmente sua parte oriental, conformando-se com a ascensão dos militares ao poder no país.

Era uma época difícil expressada em falas como "naquela época era tudo atrasado mesmo" e "era tempo de sofrimento" (ENTREVISTADO 1, 4 nov. 2018). Denota-se a dicotomia homem-natureza, haja vista que os indivíduos presentes nessas bordas amazônicas, em muitos casos vindos de fora, não estavam totalmente adaptados à vida na selva e soma-se $a$ isso a total falta de infraestrutura relegada por parte do Estado.

Observa-se nas falas dos entrevistados as condições subalternas a que se submetiam para sobreviver, em muitos casos propiciando uma fobia ao passado. Todavia, é nítida a contradição presente em muitos dos discursos obtidos como "era um tempo difícil, atrasado, mas era bom". O "bom" se refere ao caráter de subsistência predominante nesses locais, até então pouco impactados por técnicas agrícolas e urbanização. Segundo atesta o entrevistado 3 ,

Esse tempo, apesar do sofrimento, era bom por causa do que já falei do tatu, da bacaba, açaí, cupu, do puba, do uxi (...). O uxi é uma fruta do tamanho de um ovo de casca ríspida e dentro tem uma polpa que você põe açúcar e desmancha que nem abacate, aí a gente tirava o leite e comia ele que nem açaí (nov. 2018, informação verbal).

Essas pessoas tinham um modo de vida, geralmente nômade, já que na época chuvosa iam para a selva trabalhar com a castanha e na estiagem se atarefavam em outras atividades ou se mantinham em período sabático em Marabá, à espera do início das chuvas.

O trabalho no castanhal para quem possuía família era mais difícil, e geralmente os castanheiros levavam suas famílias. No caso dos homens de família, o lado positivo se dá pelo fato de poderem dedicar-se totalmente à atividade da coleta e corte do ouriço, tendo em vista que a mulher e os filhos executariam outras atividades como cozinhar e lavar, diferentemente do solteiro, que conciliava o

$\begin{array}{llllll}\text { Caminhos de Geografia } & \text { Uberlândia - MG } & \text { v. 21, n. 73 } & \text { Mar/2020 } & \text { p. 415-428 } & \text { Página } 425\end{array}$


preparatório das refeições com as atividades extrativistas. Na mata era necessário saber aproveitar os bens oferecidos por ela desde a caça até as plantas, caso contrário a dependência dos produtos do patrão aumentaria e certamente a possibilidade de ficar em déficit seria bem maior.

No tempo desta pesquisa, os castanheiros do povoado Fortaleza diversificaram suas formas de trabalho e os que ainda coletam e cortam castanhas o fazem somente para consumo próprio, pois os grandes castanhais existentes na região desapareceram. Ao serem questionados sobre a prática de tal atividade atualmente, os castanheiros de Fortaleza têm reações diferentes: uns tem um pequeno ponto de comércio, localizado na principal rua da localidade, no qual vende produtos como a carne de suínos. Em algumas de suas falas ele confirma: "A vida hoje é essa, comprar um bichim véi pra matar e vender, aí dá pra ir escapando" (nov. 2018, informação verbal).

Um entrevistado, castanheiro, não mais trabalha na coleta do fruto. Um outro morador do povoado Floresta coleta a castanha de forma esporádica. Ambos, após a queda da produção das castanhas, passaram a trabalhar em outras atividades rurais ligadas a agropecuária. A figura 5, logo abaixo, demonstra as atividades exercidas pelos entrevistados no passado (cor verde) e hoje (cor azul).

Figura 5 - Diagrama do passado e presente das atividades exercidas pelos entrevistados.

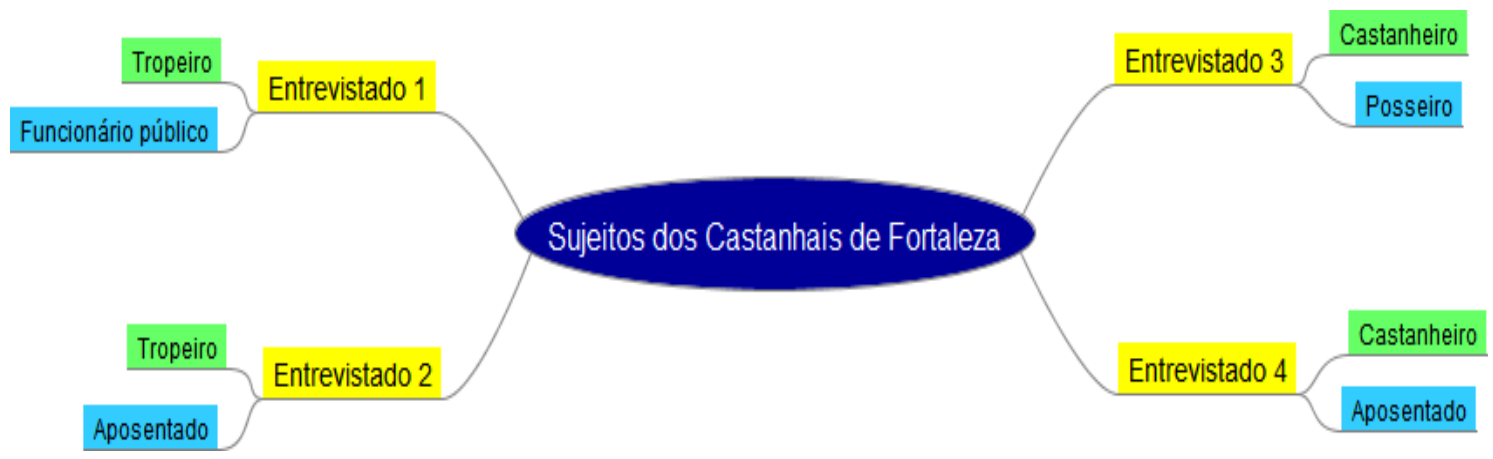

Fonte: autor (2018).

Os entrevistados 1 e 3 são mais jovens e trabalharam nos castanhais enquanto adolescentes, já no início da idade adulta se inseriram no processo do extrativismo da castanha quando este já se aproximava do declínio. Outra similaridade se dá pelo fato de os dois terem se tornado posseiros após a apropriação dos castanhais e, atualmente, o entrevistado 3 ainda possui terra localizada nas proximidades do povoado e tem um ponto alugado onde montou uma oficina de motocicletas. $\mathrm{O}$ outro, o único nascido na região do Itacaiúnas, empregou-se em uma escola do povoado como vigia e, nas horas vagas, quando aparece serviço, trabalha no campo, pois ao longo da vida sempre esteve ligado a duas atividades, a extrativa e a agropastoril.

Nos diálogos construídos com tais sujeitos nota-se a nostalgia com que se recordam do tempo da castanha e devido às condições de trabalho submetidos nesse período, que sempre é lembrado como um "tempo sofrido" em que "tudo era atrasado" (nov. 2018, informação verbal). Na conjunção dessas memórias existe a contradição constatada pelas boas lembranças e a negação de reviver aquela época caso fosse possível.

Nenhum deles enriqueceu com a exploração da castanha, apesar de o entrevistado 1 relatar que "era o tempo melhor pra se ganhar dinheiro aqui nesta região, moço! Dava dinheiro demais a castanha" (nov. 2018, informação verbal). Mesmo com toda a força da economia da castanha nessa época, essas pessoas estavam na base da atividade e participavam de uma parcela irrisória do montante gerado nesse ciclo. Contudo, todos eles atualmente possuem residências próprias e encontraram outros modos de trabalho.

\section{TRABALHO E IDENTIDADE: OS CASTANHEIROS DO POVOADO FORTALEZA}

Mesmo sendo visto o trabalho castanheiro como difícil e sofrido, a época da castanha para os castanheiros de Fortaleza remonta a bons momentos vividos em meios aos castanhais. A diversidade de animais da natureza é expressa na fala do entrevistado 4: "Naquela época era tudo atrasado mesmo, no barracão a gente tinha que ir cedo pra arrumar o local de ficar. Não era bom, não, mas se livrava. Tinha muito peixe, caça, dava de ir escapando bom danado" (nov. 2018, informação verbal). Isso

$\begin{array}{llllll}\text { Caminhos de Geografia } & \text { Uberlândia - MG } & \text { v. 21, n. 73 } & \text { Mar/2020 } & \text { p. 415-428 } & \text { Página } 426\end{array}$


contrasta com os dias atuais, em que os mesmos indivíduos, anteriormente acostumados com a generosidade da terra, não têm mais acesso livre a esses bens naturais.

Até mesmo as situações de trabalho enfrentadas ficavam em segundo plano quando recordam quão bom era ir para a mata:

Aí quando chovia você já ficava com vontade de ir pra mata e você não ganhava nada, era só a comida. Dinheiro, não. Era um serviço meio nojento, mas você gosta. Mas é meio doído, tá chovendo e você sabe que tem que andar uns $3 \mathrm{~km}$ na mata pra cortar castanha (ENTREVISTADO 03, nov. 2018).

Em contrapartida, a exploração e a servidão a eles imposta pelos senhores dos castanhais dificultou a criação de uma identidade por parte deles com o trabalho castanheiro. Os paneiros (coletores da paina) pesados cheio de ouriços nas costas, a malária, a fraude na medição da castanha e o preço exorbitante dos produtos do barracão, sendo essas apenas algumas das intempéries ligadas ao trabalho do castanheiro, tornam mais entendível o porquê dessa identidade do "ser castanheiro" ser diluída, tanto que, quando os castanhais passaram a ser ameaçados por outras atividades, não houve da parte de tais indivíduos um movimento de articulação para proteger os castanhais; pelo contrário, eles certamente viram a implantação desses novos meios de produção como uma forma de se libertarem da extração da castanha e viverem de uma forma mais autônoma, conseguindo seu próprio pedaço de terra onde poderiam plantar, criar sem a interferência de patrões e com a possibilidade de se dedicar apenas a um trabalho durante todo $\mathrm{o}$ ano, em contraste com a sazonalidade da exploração da castanha.

No entanto, a ideia de ter uma nova vida voltada para a lógica agropecuária não se mostrou tão bela. Dos castanheiros e tropeiros com quais se dialogou, somente um ainda possui terra, mas pequena e insuficiente para sobreviver, tanto que precisou montar outros negócios no povoado. Todos possuíram terra ou trabalharam em algum momento em terras alheias, mas hoje exercem atividades distintas e já não possuem terras ou mesmo vigor para com elas lidar. Portanto, a atual situação dos castanheiros de Fortaleza, despossuídos da terra e dos castanhais, traz à memória o passado e, ao se direcionarem ao período vivido embaixo das castanheiras, surge o paradoxo do tempo que era sofrido, mas era bom, pois tinham a natureza em suas mãos.

A atual situação dos castanheiros em Fortaleza demonstram sujeitos deslocados das conjunturas atuais do mercado da castanha. O que fazem de melhor se mostrou ultrapassado e não conseguem se encaixar nas formas produtivas atuais, por conseguinte acabam sendo direcionados a realizar trabalhos pelo simples instinto de sobrevivência, não os satisfazendo por completo e aumentando a saudade do tempo da castanha.

Apesar de fracionada, dá para falar que tais sujeitos possuem identidade com a extração da castanha, sobretudo em relação à fartura daqueles tempos e o companheirismo, geralmente, prevalecente comprova essa sensação de pertencimento. No entanto, esse pertencer foi insuficiente para os castanheiros se associarem e lutarem pela manutenção dos antigos castanhais, pois temiam a permanência do sistema de trabalho do extrativismo e, ao mesmo tempo, como grande parte da sociedade compraram o discurso do progresso prometido pelo Estado no avançar de outras frentes de produção.

\section{CONSIDERAÇÕES FINAIS}

A pesquisa elencada levantou questões sobre o extrativismo da castanha, principalmente na região do Itacaiúnas. Construiu-se diálogos referentes tanto à importância econômica dessa atividade como à posição deplorável em que se encontravam os trabalhadores nas selvas amazônicas e, também, a participação desse meio de produção para a povoação na parte leste da Amazônia.

Todavia, o tema central deste estudo foram os castanheiros de Fortaleza, sendo as questões citadas vistas como base para entender a lógica da castanha. Sobre os castanheiros de Fortaleza foram feitas reflexões relacionadas ao seus territórios, comparação e análise no que diz respeito aos seus passados e presentes, centrando-se nos modos de vida, e por fim verificou-se o pertencimento de tais sujeitos com o trabalho nos castanhais e identidade castanheira.

Ao nos voltarmos à problemática disposta no início deste trabalho e verificar os resultados obtidos com a pesquisa, percebe-se que a temática é complexa, principalmente no que se refere a construção identitária do castanheiro. No entanto, trata-se de uma temática muito densa, a qual necessita de ampliação e um melhor planejamento para responder as inquietudes levantadas.

$\begin{array}{llllll}\text { Caminhos de Geografia } & \text { Uberlândia - MG } & \text { v. 21, n. 73 } & \text { Mar/2020 } & \text { p. 415-428 } & \text { Página } 427\end{array}$


Para o povoado Fortaleza, recomendam-se estudos focados nas atividades econômicas indutoras na região, castanha no passado e pecuária na atualidade, e também demarcar um paralelo entre tais ciclos. Referente aos castanheiros desse povoado há outras questões a discutir, como a contribuição deles para a constituição de povoações onde ficavam antigos pontos e praças da castanha, como é o caso de Fortaleza. A pesquisa sobre os saberes dos castanheiros nos castanhais é importante para a ampliação e levantamentos de novos debates geográficos sobre o extrativismo da castanha-do-pará e sua importância na fronteira humana e na formação dos territórios na Amazônia.

\section{REFERÊNCIAS BIBLIOGRÁFICAS}

ALMEIDA, José Jonas. Do extrativismo à domesticação: as possibilidades da Castanha-doPará. 2015. 304 f. Tese (Doutorado) - Curso de História, USP, São Paulo, 2015.

BRAZ, Ademir. Rebanho de Pedras \& Esta Terra. Poesias. 2ª edições. Marabá: Grafecort, 2003.

DIAS, Catarina Vergolino. Marabá - Centro Comercial da Castanha. Revista Brasileira de Geografia, Rio de Janeiro, v. 4, p.383-429, 1958. Trimestral.

DIAS, Catarina Vergolino. Aspectos Geográficos do Comércio da Castanha no Médio Tocantins. Revista Brasileira de Geografia, Rio de Janeiro, v. 4, p.517-533, 1959. Trimestral.

EMMI, Marília Ferreira. Os castanhais do Tocantins e a Indústria Extrativa no Pará até a década de 1960. Paper do NAEA 166. Belém: UFPA, out. 2002, p. 03.

HAESBAERT, Rogério. Da desterritorialização à multiterritorialidades. In: Anais... Encontro de Geógrafos da América Latina, 10, São Paulo. Anais... São Paulo: USP, 2005. p. 01-15.

MARTINS, José de Souza. O tempo da fronteira: retorno à controvérsia sobre o tempo histórico da frente de expansão e da frente pioneira. Tempo Social. USP/São Paulo. v. 8, n. 1, p. 25-70, 11. 1996. https://doi.org/10.1590/ts.v8i1.86141.

MORAES, Maria Aparecida. Errantes do fim do século. São Paulo: Editora Unesp, 1999.

OLIVEIRA, Américo Barbosa de. Considerações sobre a exploração da castanha no Baixo e Médio Tocantins. Revista Brasileira de Geografia, Rio de Janeiro, v. 1, p.3-16, jan. 1940. Mensal.

RAFFESTIN, Claude. Por uma Geografia do poder. São Paulo: Ática, 1993. 269 p.

SENNETT, Richard. A corrosão do Caráter: consequências pessoais do trabalho no novo capitalismo. 14. ed. Rio de Janeiro: Record, 2009.

SILVA, Idelma Santiago da. Migração e Cultura no Sudeste do Pará. 2006. 181 f. Dissertação (Mestrado) - Curso de História, Faculdade de Ciências Humanas e Filosofia, UFG, Goiânia, 2006

VERDEJO, Miguel Expósito. Diagnóstico rural participativo: um guia prático. Brasília/DF: Ascar, 2006. $62 \mathrm{p}$.

\section{LISTA DOS ENTREVISTADOS}

Entrevistado 1 - Memórias dos sujeitos dos castanhais do povoado Fortaleza. Local da entrevista: residência do entrevistado. Data: 3/11/2018.

Entrevistado 2 - Memórias dos sujeitos dos castanhais do povoado Fortaleza. Local da entrevista: residência do entrevistado. Data: 2/11/2018.

Entrevistado 3 - Memórias dos sujeitos dos castanhais do povoado Fortaleza. Local da entrevista: residência do entrevistado. Data: 3/11/2018.

Entrevistado 4 - Memórias dos sujeitos dos castanhais do povoado Fortaleza. Local da entrevista: residência do entrevistado. Data: 4/11/2018.

Recebido em: 30/06/2019

Aceito para publicação em: 29/10/2019

$\begin{array}{llllll}\text { Caminhos de Geografia } & \text { Uberlândia - MG } & \text { v. 21, n. 73 } & \text { Mar/2020 } & \text { p. 415-428 } & \text { Página } 428\end{array}$

